\title{
MANUTENÇÃO DA BARATA D'ÁGUA GIGANTE (GEN. LETHOCERUS) NO LABORATÓRIO
}

\author{
MARIA CHRISTINA BARROS SAWAYA \\ Inst. fuer Zellphysiologie - Univ. Bochum - Alemanha \\ Ocidental - Dept. ${ }^{\circ}$ Fisiologia Geral do Inst. Biociências \\ da USP.
}

\section{RESUMO}

Para estudo da fisiologia do músculo do voo da Barata d'água gigante (gên. Lethocerus) (oscilação miogênica nos músculos assincrônicos), aproveitou-se a oportunidade para estudar vários aspectos da biologia de Lethocerus, que ocorre nas Américas. A alimentação consistiu de peixes, sapos, rãs, grandes insetos, etc. Construiram-se pequenos aquários de plástico providos de grades para impedir a evasão das baratas. O dispositivo permitiu uma série interessante de observações, relativas não só à alimentação, como respiração, ovipostura, etc.

\section{KEEPING GIANT WATERBUG (GEN. LETHOCERUS) IN CAPTIVITY}

\begin{abstract}
For the study of the flight muscles (myogenic oscillation of the assynchronous flight muscles) of the giant water bugs (gen. Lethocerus) several observations have been made of by plastic material and provided with a net to avoid the animals to escape. The observations were accorded on feeding, respiration and egging have been recorded.
\end{abstract}

\section{INTRODUÇÃO}

Nos músculos assincrônicos do voo da barata d'água gigante (gen. Lethocerus) pôde pela primeira vez ser demonstrado o fenômeno da oscilação miogênica. Este fenômeno caracteriza-se pelo fato de que a estrutura contractil das fibras musculares não é somente ativada por uma excitação nervosa na membrana muscular mas, ela pode também ser diretamente ativada por uma extensão mecânica do músculo (Pringle 1954; Machin, Pringle 1959; Jewell, Rüegg 1966). Com a demonstração deste fenômeno aceita-se então uma ativação mecânica

Número especial em homenagem ao Prof. Dr. Paulo Sawaya, no ano jubilar dé seu magistério. 
direta da estrutura contractil das fibras musculares. Uma vez que a ativação mecânica já pôde também ser demonstrada em fibras do músculo esquelético (Rüegg, Steiger, Schädler 1970; Heinl 1972) e do músculo do coração de diferentes animais (Heinl, Herzig, Sawaya, Steiger 1973) o esclarecimento deste mecanismo é de importância fundamental para a compreensão do funcionamento, em termos moleculares, da estrutura contractil.

Devido à extrema regularidade da estrutura contractil de suas miofibrilas os músculos assincrônicos do vôo desses insetos aquáticos têm sido nos últimos anos muito usados em pesquisas sobre a estrutura da fibra muscular. Esses estudos tem sido principalmente realizado com o auxílio do microscópio eletrônico e através da difração de raio X (Reedy, Holmes, Tregear 1966; Reedy 1968).

Assim sendo a manutenção das baratas d'água gigantes no laboratório é bastante interessante. Neste trabalho dediquei atenção à biologia desses insetos e à sua manutenção, da forma mais simples possivel, no laboratório.

Biologia da barata d’água gigante - gen. Lethocerus

As baratas d'água Lethocerus maximus De Carlo com ca. de 100 $\mathrm{mm}$ de comprimento e ca. de $35 \mathrm{~mm}$ de largura e Lethocerus annulipes (Herrich-Schaffer) com ca. de $65 \mathrm{~cm}$ de comprimento e $23 \mathrm{~cm}$ de largura, são Hemípteros da família Belostomatidae, que ocorrem na região tropical e temperada do Continente Americano. A primeira ocorre somente na América Latina (De Carlo, 1938) e a segunda tem uma dispersão maior, desde os Estados Unidos até a Argentina (Cummings, 1933).

São insetos de cor castanha, achatados dorsoventralmente e compõem-se de uma pequena cabeça unida rigidamente ao protorax, um protorax em forma de trapézio, um meso e metatorax fundidos e abdome. Na cabeça observam-se principalmente os dois olhos bastante grandes com ca. de 5000 omatídios em cada um (Cullen, 1969); não possuem ocelos e as antenas estão escondidas em forma de uma pequena bolsa atrás dos olhos. A característica marcante de $L$. $m \alpha$ ximus é a ausência da carena média na região interocular, da cor amarelada com apenas um filete pardo no centro desta região e ainda, na sua parte posterior, a região interocular é mais 
estreita que o diâmetro de um olho (fig. 1). O aparelho bucal funde-se numa curta tromba obtusa. No segmento torácico estão localizados os três pares de patas: a pata anterior é raptorial e tem o femur em $L$. maximus não muito dilatado mas, relativamente, muito dilatado em $L$. annulipes (fig. 2); o femur possue um vinco na regiāo ventral, no qual a tíbia pode se encaixar (Hungerford, 1919); o tarso está fixo à tíbia e tem uma pequena unha na ponta. As patas posteriores são achatadas horizontalmente, cobertas de pelos e servem para a natação; seus tarsos estão unidos por articulações com as respectivas tíbias, as quais tem, cada uma, duas unhas maiores que a da tíbia anterior. As asas anteriores — os élitros - são quitinosas e cobrem totalmente o abdome, possuindo na parte caudal uma região membra-

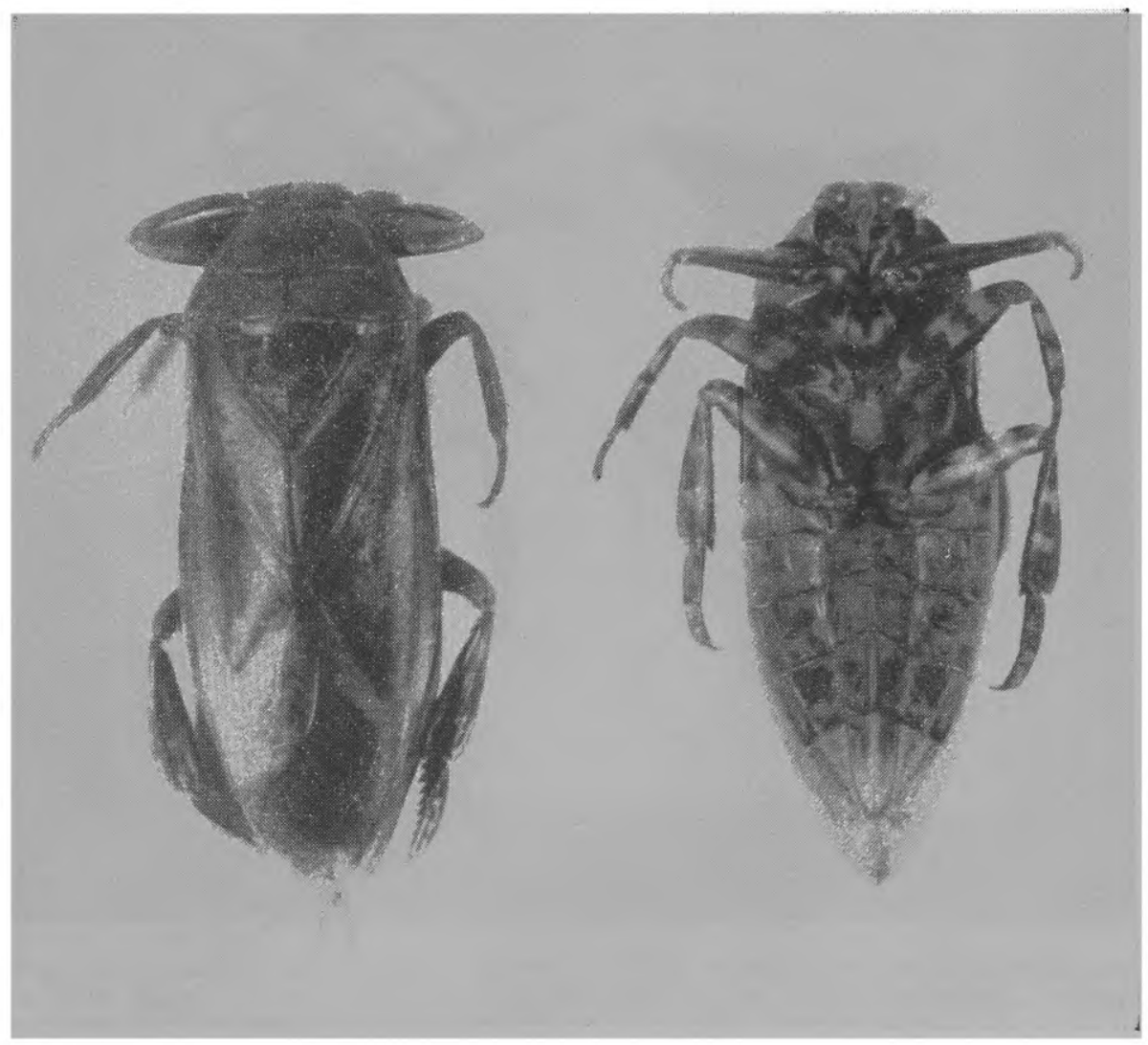

Fig. 1 - Lethocerus maximus De Carlo - Vista dorsal (à esquerda) e vista ventral (à direita). Descrição no texto. (Foto: A. Heinl). 
nosa com muitas nervuras, enquanto que as asas posteriores, de cor amarela clara, bastante finas, delicadas, recobrem somente a parte anterior do abdome (Cummings, 1933; De Carlo, 1938; Cullen, 1969). $\mathrm{Na}$ região ventral do abdome de $L$. annulipes duas faixas pretas longitudinais, que percorrem toda extensão do abdome até o segmento do opérculo genital, constituem uma característica marcante desta espécie (fig. 3).

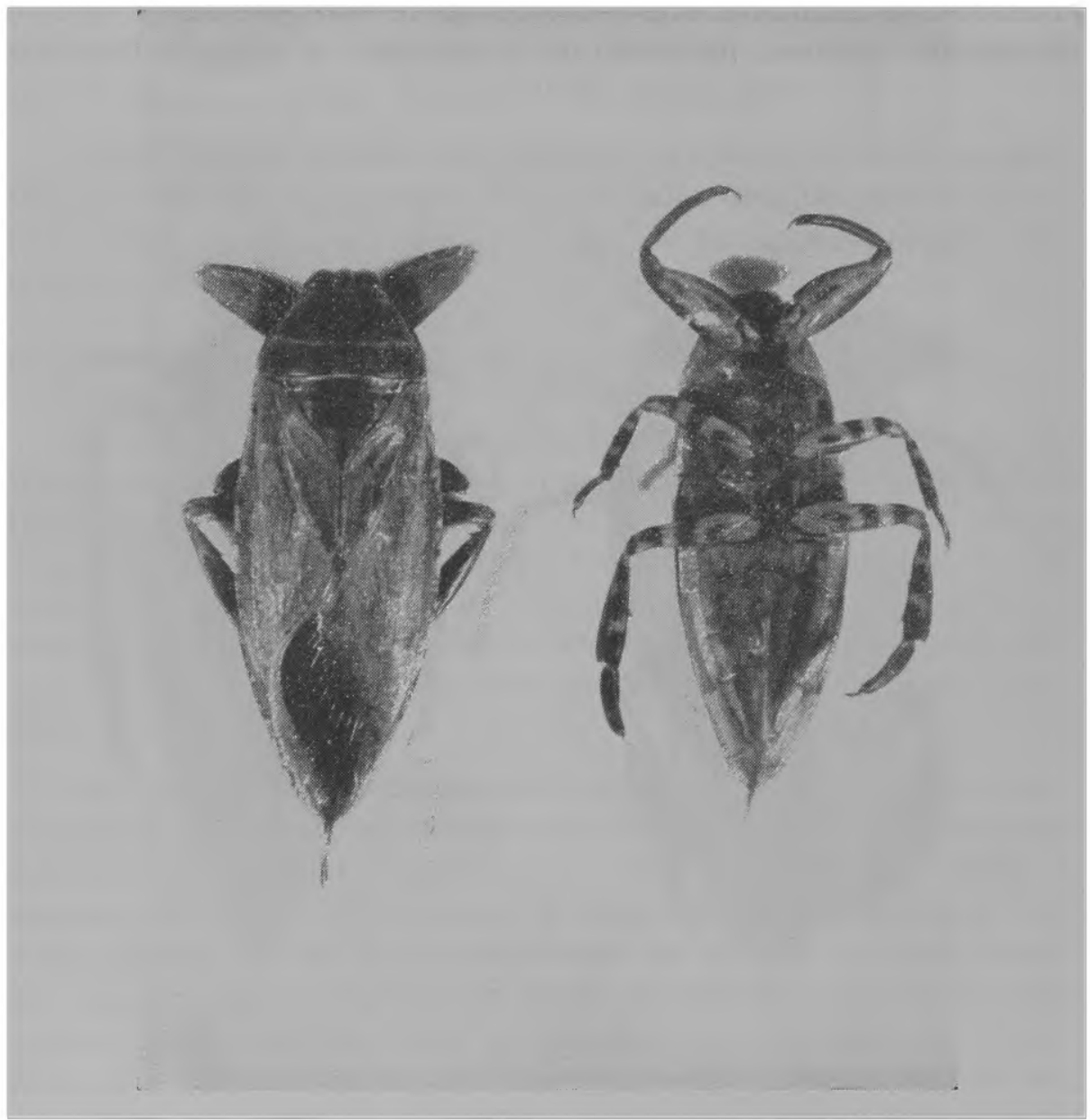

Fig. 2 - Lethocerus annulipes (Herrich-Schaffer) - Vista dorsal (à esquerda) e vista ventral (à direita). Descrição no texto. (Foto: A. Heinl). 


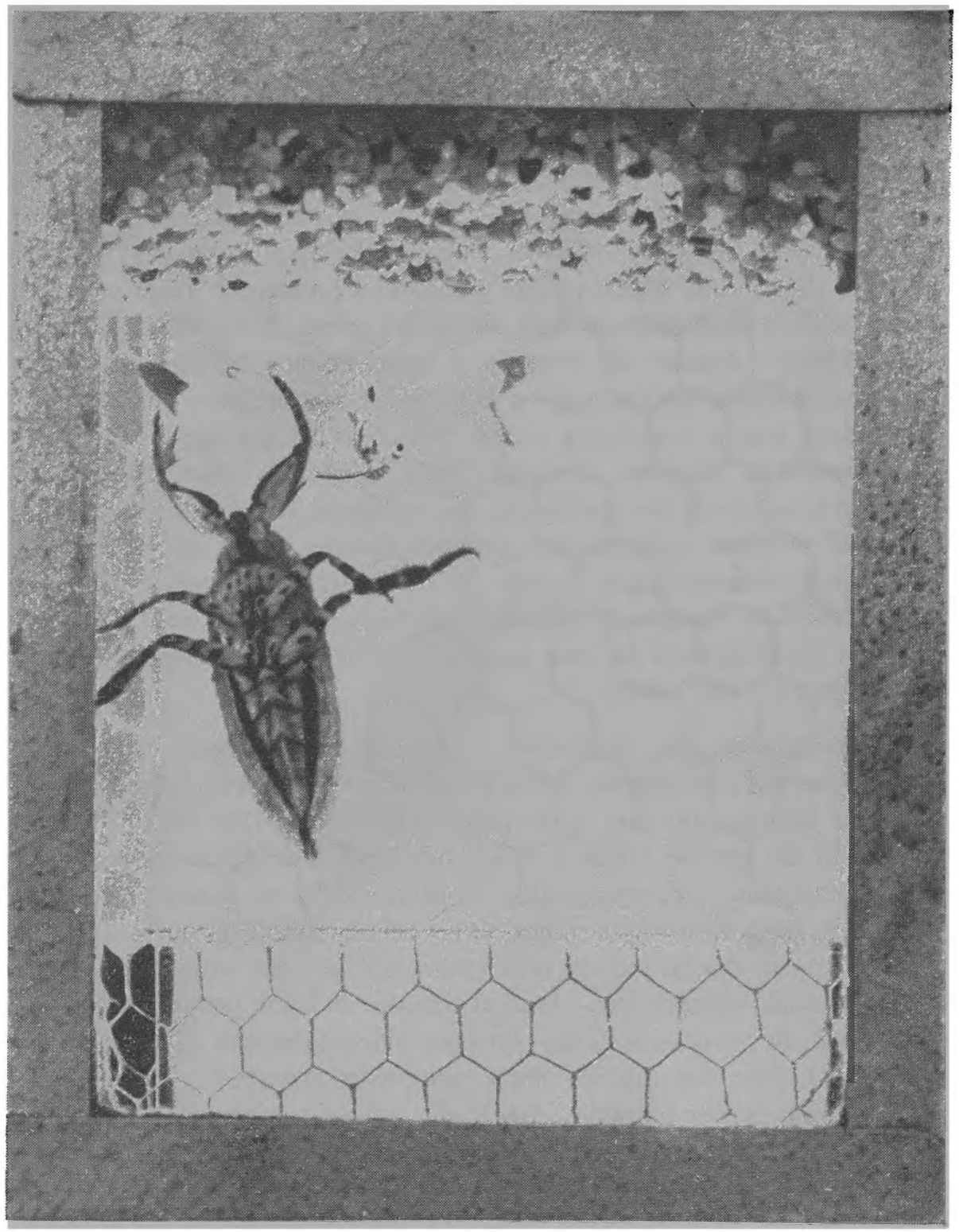

Fig. 3 - Lethocerus annulipes (H.S.) - Vista ventral, no aquário, mostrando as duas faixas pretas longitudinais características na região abdominal. Maiores pormenores ver texto. (Foto: A. Heinl). 
As baratas d'água $L$. maximus provieram principalmente de Trindade (temperatura média durante o dia ca. $30^{\circ} \mathrm{C}$, durante a noite ca. $24^{\circ} \mathrm{C}$, precipitação anual de chuvas ca. $215 \mathrm{~mm}$ ) (Cullen, 1969) e $L$. annulipes do Estado de São Paulo, Brasil (temperatura média diurna ca. $22^{\circ} \mathrm{C}$, noturna $18^{\circ} \mathrm{C}$ ). São insetos que vivem em pântanos, lagos grandes e pequenos, onde se agarram abaixo da superfície da água a plantas aquáticas (por exemplo - Salvinaceae, Nymphaceae). Através de sifões retrácteis (Hungerford, 1919), que emergem da extremidade posterior livre do abdome as baratas podem bombear ar atmosférico, ou das bolhas de ar presas às plantas aquáticas, para o reservatório interno localizado no lado dorsal do corpo (Torre-Bueno, 1916; Cullen, 1969). Apesar de viverem a maior parte de suas vidas na água essas baratas podem voar e a grandes distâncias. Os batimentos das asas tem a frequência de ca. $22-25$ ciclos por segundo a $35^{\circ} \mathrm{C}$ em L. maximus (Barber, Pringle, 1966). Segundo estes autores as baratas d'água voam em média ca. de, somente, 3-4 vezes por ano e, sobretudo, durante a época das grandes chuvas e em noites de lua cheia, provavelmente para mudar de "habitat" Porisso é possivel coletá-las não só durante o dia nas plantas aquáticas como, também, durante a noite através de uma armadilha iluminada, colocada à beira de um lago (Cullen, 1969).

As baratas d'água alimentam-se de pequenos peixes, sapos, rãs, grandes insetos, coleópteros, presas estas que às vezes chegam a ter dimensões maiores do que a do próprio predador (De Carlo, 1940). $\mathrm{Na}$ posição de ataque (figs. 3 e 4), que se pôde observar inúmeras vezes no cativeiro, i.é, no aquário do laboratório, as patas anteriores se projetam para frente e permanecem separadas uma da outra. Assim a barata d'água espera imovel pela presa, até que um animal se movimente nas suas vizinhanças. Provavelmente o fator propulsor da rápida reação de prender a presa provém principalmente de uma excitação visual, uma vez que os olhos complexos projetados para frente permitem uma visão binocular para um acurado registro das distâncias. É possivel que a barata d'água se aperceba ainda da presença de um animal em suas vizinhanças através de pelos sensíveis a correntes aquáticas localizados na região anterior do corpo (Dingle, 1961; Cullen, 1969). As patas anteriores movimentam-se muito rapidamente nesta ação de captura da presa (fig. 5). Esta é mantida segura por dois ou mesmo pelos três pares de patas e em seguida paralisada pela picada com a tromba. A secreção paralisante dissolve provavelmente 


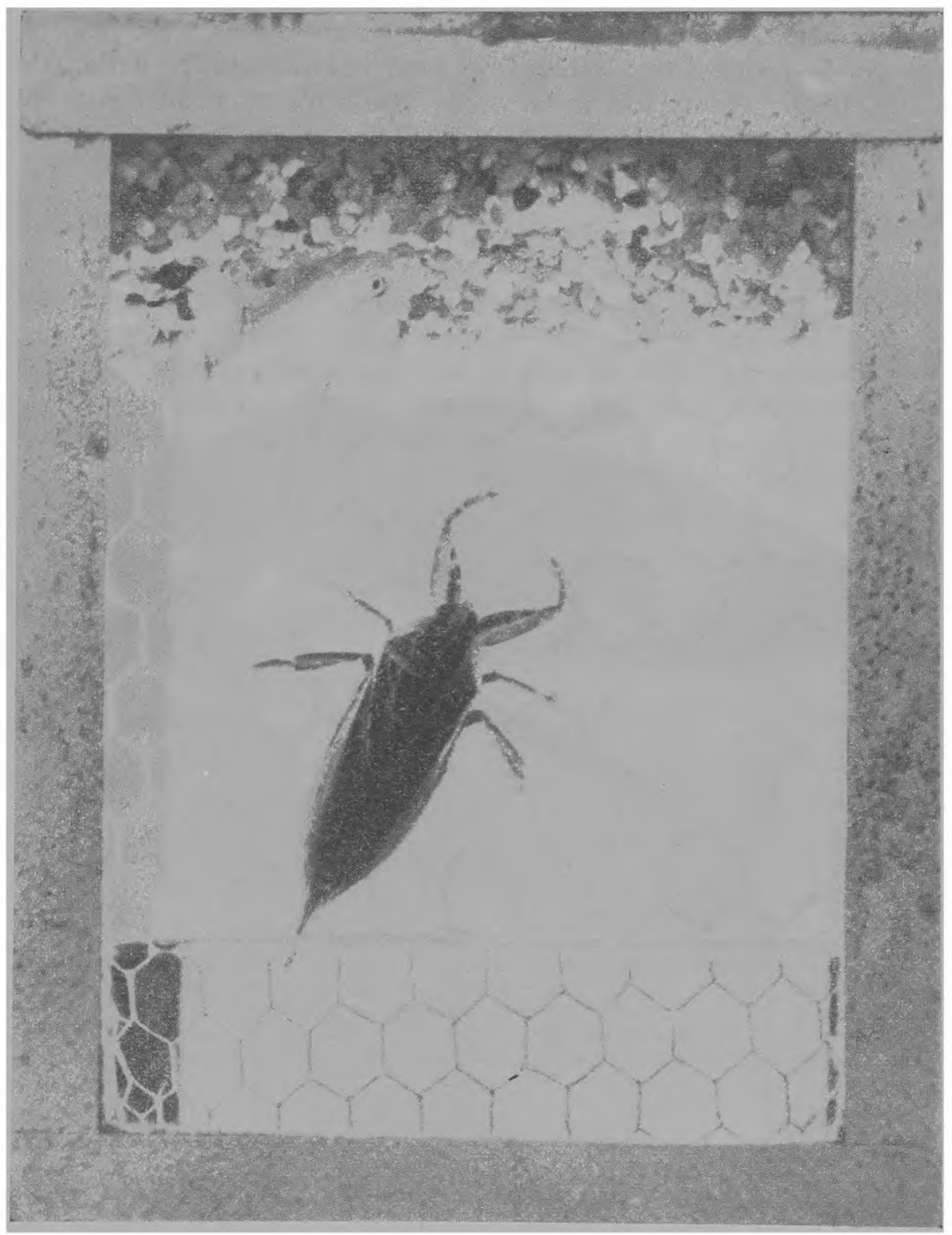

Fig. 4 - Lethocerus annulipes (H.S.) em posição de ataque: as patas dianteiras raptoriais estão distendidas para frente para capturar um peixe Carassius; com os outros pares de patas a barata d'água se prende à grade. Os dois sifóes, que servem para a respiração situados no segmento caudal, erguem-se até a superfície da água. (Foto: A. Heinl). 
os tecidos moles interiores do animal, os quais são então, juntamente com o sangue, longamente sugados pela barata d'água. No homem, sua picada provoca uma inflamação local relativamente extensa (De Carlo, 1940). O principal predador da barata d'água $L$. maximus em Trinidad constitue o Caiman sclerops (Cullen, 1969).

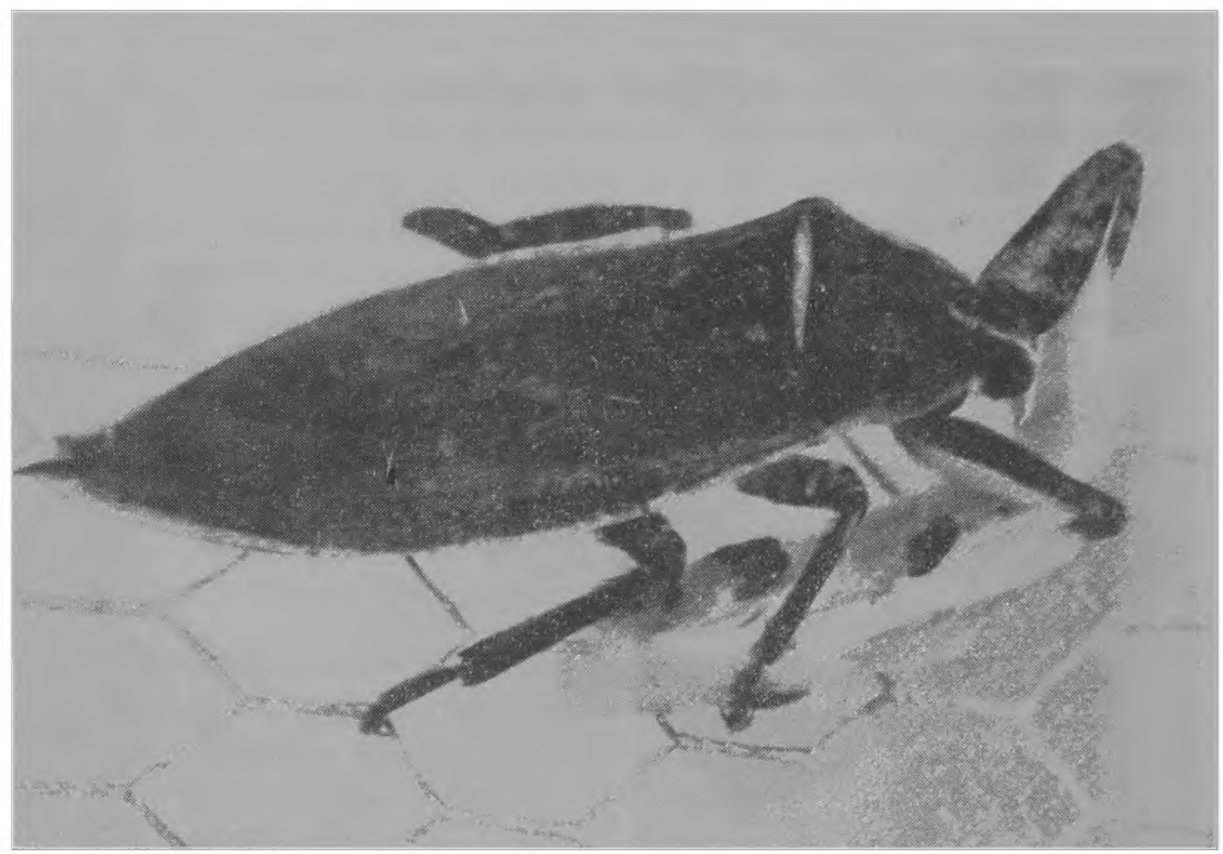

Fig. 5 - Lethocerus maximus De Carlo, com o peixe Carassius aprisionado. A barata d'água agarra o peixe com as patas dianteiras e procura, com a curta tromba, uma parte mais mole (debaixo de uma escama) para picar a presa. A cabeça e o protorax dobram-se para frente, uma vez que a cabeça não pode se mover devido à sólida união com o protorax. (Foto: B. Poeschmann).

Os representantes do gênero Lethocerus põem as suas massas de ovos sobre ramos de plantas aquáticas na superfície d'água. Os animais em ca. de 90 dias passam à fase adulta. Somente então, algumas semanas mais tarde, as asas, os músculos do vôo e a cutícula estão totalmente desenvolvidos, o que permite à barata voar (Cullen, 1969). 
Manutenção no laboratório de baratas d’água do gen. Lethocerus

Foi possivel manter em cativeiro e observar os espécimes vivos de $L$. maximus e $L$. annulipes durante vários meses numa instalação especialmente construida para este fim (fig. 6) no laboratório.

O fundo de uma cuba de plástico foi coberto com bastante cascalho (ca. $2 \mathrm{~cm}$ de altura) sobre o qual se colocou água de aquário $\left(20-25^{\circ} \mathrm{C}\right)$ até ca. $10 \mathrm{~cm}$ de altura. A água do aquário foi arejada e circulava através de uma bomba d'água com filtro de carvão para ser mantida limpa. A cuba de plástico foi dividida em 6 compartimentos, para impedir que as baratas d'água se devorassem umas às outras. Aliás, fenômeno este, que só pôde ser observado quando havia escassez de alimento. A parede exterior dos compartimentos foi construida com uma grade de plástico de poros pequenos, na qual as baratas podiam se prender. As divisões interiores dos compartimentos, como também a tampa dos mesmos eram de plexiglass.

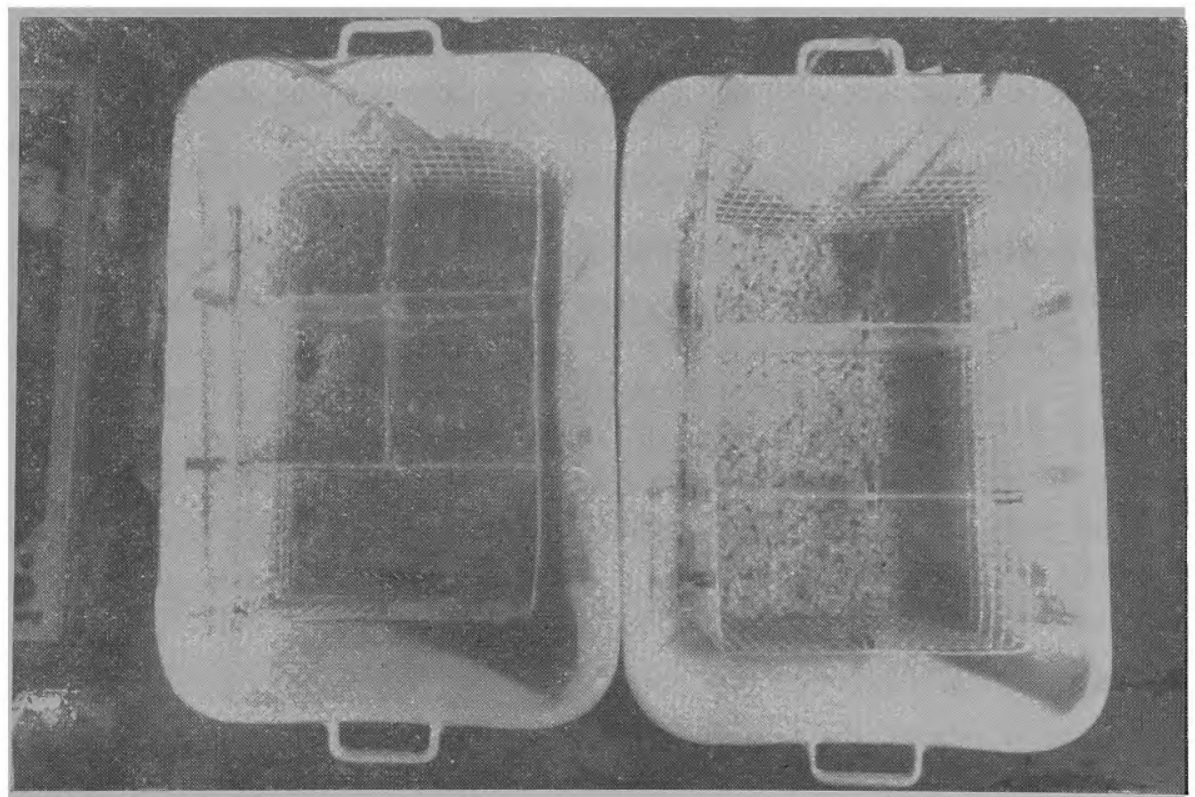

Fig. 6 - Aquários para a manutenção das baratas d'água no laboratório: nas cubas de plástico estão colocadas seis celas, cujas paredes exteriores são formadas por um engradado de plástico com poros pequenos. Tanto as divisōes internas, como as tampas (não aparecem na foto) das respectivas celas, são de plexiglass. Os dois tubos de borracha mais grossos servem para a circulação da água, o tubo fino para a circulação do ar na água do aquário. (Foto: A. Heinl). 
As cubas assim preparadas foram colocadas próximas a uma grande janela com bastante possibilidade de receber a luz solar, à temperatura ambiente de ca. $20-25^{\circ} \mathrm{C}$. Toda a instalação foi, pelo menos uma vez por mês, lavada com detergente líquido e muita água da torneira e o filtro de carvão trocado.

As baratas d'água foram alimentadas com peixes Carassius (ca. 5-10 $\mathrm{cm}$ de comprimento). Na posição de ataque elas grudavam na grade dentro d'água e deixavam as patas anteriores estiradas para frente e livres (figs. 3 e 4). Nos primeiros dias, após a chegada ao laboratório, elas devoravam cada uma ca. de um peixe por dia; com o tempo comiam menos (ca. 1-2 peixes por semana cada uma). Durante o dia, as baratas permaneciam quase sempre na posição de "repouso" Mantinham-se presas à grade dentro d'água, com a cabeça voltada para o fundo da cuba e os dois sifões sobre o nivel d'água, para permitir a constante respiração. Em dias úmidos e à noite eram então ativas e procuravam uma oportunidade para voar. Às vezes conseguiam até mesmo levantar a tampa de plexiglass do respectivo compartimento e voar no laboratório. O fato de que essas baratas não podem viver muito tempo fora d'água foi também observado no laboratório. Alguns exemplares que, por diferentes motivos, não conseguiram retornar a água e ficaram presos na grade mostraram-se completamente ressecados após $24 \mathrm{~h}$.

Vários exemplares da espécie $L$. annulipes colocaram logo após a chegada no laboratório (até 5 dias após a chegada) várias massas de ovos (ca. 10-12 ovos por massa) no fundo da cuba do aquário. Os ovos estavam unidos e envolvidos por uma substância gelatinosa transparente e apresentavam logo de início uma cor amarela clara com listras longitudinais verde claro. Com o passar dos dias os ovos tomavam uma coloração escura; todas as tentativas levadas a cabo, para permitir o desenvolvimento desses ovos não tiveram êxito. Quando os ovos eram deixados nas cubas junto com as baratas d'água, eles eram após poucas horas sugados pelas próprias baratas.

Com o passar do tempo, as baratas incorporavam maior quantidade de tecido adiposo, o qual podia ser constatado durante a dissecção para a preparação do músculo do vôo. No entretanto, a qualidade do respectivo músculo não parecia ser influenciada por tal fenômeno. Não se observou, tampouco, degeneração muscular durante a manutenção das baratas d'água em cativeiro. 
A G R A D E C I M E T O S

Agradeço A. Heint e B. Poeschrnann pela parte fotográfica e à Deutsche Forschungsgerneinschaft e à Reitoria da Universidade de São Paulo pelo auxílio prestado.

\section{B I B L I O G R A F I A}

BARBER, S. B. \& PRINGLE, J. W. S. (1966) - Proc. Roy. Soc. B. London 164: 21 .

CULlen, M. J. (1969) - Proc. Roy. ent. Soc. (A) 44:123.

CUMMINGS, C. (1933) - Kans. Univ. Sci. Bull. 21:197.

DE CARLO, J. A. (1938) - Entomologia 155:189.

(1940) - Prim. Jorn. entomoepid. argen. 6. ${ }^{\mathbf{a}}$ sess. cient. 715.

DINGLE, H. (1961) - Biol. Bull. mar. biol. Lab., Woods Hole 121:117.

HEINL, P (1972) - Pfluegers Arch. 333:213.

HEINL, P.; HERZIB, J.; SAWAYA, M. C. B. \& STEIGER, G. (1973) - 41. Tag.

Deutsche Physiol. Gesellech. Nr. 23.

HUNGERFORD, H. (1919) - Kans. Univ. Sci. Bull. 11:1.

JEWELL, B. R. \& RÜEGG, J. C. (1966) - Proc. Roy. Soc. B. London 164:428.

MACHIN, K. E. \& PRINGLE, J. W. S. (1959) - Proc. Roy. Soc. B. London 151:204.

PRINGLE, J. W. S. (1954) - J. Physiol. 124:169.

REEDY, M. K. (1968) - J. Mol. Biol. 31:155.

; HOLMES, K. C. \& TREGEAR, R. T. (1966) - Nature 20\%:1276.

RÜEGG, J. C.; STEIGER, G. J. \& SCHÄDLER, M. (1970) - Pfluegers Arch. 319:139.

TORRE-BUENO, J. R. (1916) - Ann. Ent. Soc. Am. (ver HUNGERTORD, 1919). 
